\title{
Hours, Safety, Security Concerns: Issues, Context, Resources, and Checklists
}

\author{
by Margaret Foote and Teresa L. McManus
}

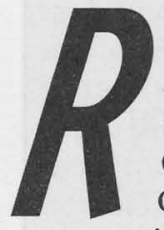

eports of libraries offering extended hours of service, sometimes rumored to be twenty-four hours a day, seven days a week, have been circulating in North Carolina. Interest in extended hours is widespread. Consider, as an example, three responses to a user satisfaction survey at Fayetteville State University's Charles Chesnutt Library, Spring 1999:

I think that there should be an all-night open use computer lab and the library should operate twentyfour hours instead of just specified amounts of time. I really think that the library should look towards having an all-night library for those who have jobs and just cannot get to the library in the time that is set.

The library is closed during holidays when students who work would be able to access these services. This is not true for NCSU and UNC libraries.

To learn more about safety and security concerns related to extended hours, and to gather data on hours and pressures for extended hours, the authors sent surveys to 200 public and academic libraries in North Carolina in March 1999. Survey results show North Carolina libraries are facing pressures to increase hours, and that two-thirds of all respondents (68\% from academic libraries and $67 \%$ of respondents from public libraries) consider safety and security concerns to be of medium to high importance as factors in decisions about extending hours.

Protecting library resources, facilities, equipment, staff, and patrons, often with no increase in staff and a reduced level of activity, is a challenge in the context of increased hours of service. Being concerned about safety and security is realistic, as recent headlines from the June/July 1999 issue of American Libraries attest: "Murder Rampage Culminates in Colorado High School Library" and "Gunman Kills Two at Mormon Library." 1 Understanding threats to and vulnerabilities of libraries, and the extent to which increased hours magnify security and safety challenges, is important for preventing losses and promoting safety. This article provides an overview of security issues in libraries, summary data from survey respondents, and bibliographic resources for library administrators interested in enhancing safety precautions during regular and extended hours.

\section{Overview of Library Security Issues}

Security and safety concerns in libraries extend beyond issues of crime. Natural disasters, accidents, and emergencies are potential risks to safety. Injuries and emergencies occurring during periods of minimal staffing present a somewhat different set of challenges than those occurring during higher levels of staffing. Fewer staff are available to assume responsibilities for evacuating the facility, contacting emergency care providers, and managing the situation to prevent additional injuries or accidents.

Search terms that are useful for researching safety and security issues in libraries include "crimes in the library," "librarianship - occupational hazards," "working conditions," "safety measures," and "problem patrons." News accounts of bomb threats, anthrax hoaxes, arson, hate crimes, indecent exposure, murders, robbery, theft and vandalism in libraries are all too easily found. How many of us can say we work in a library where no pocketbooks or backpacks are stolen? While risks to safety and security extend beyond crime and disruptive behavior, librarians must pay particular attention to these security issues if they are to take preventive measures.

Reluctance of librarians to acknowledge problems with security is well known. When discussing "loss of inventory," librarians in the first half of the century focused on misshelving. Ralph Munn's 1935 article in Library Journal ${ }^{2}$ was indicative of a shift in librarians' thinking about "missing" books. 3,4 Thomas Shaughnessy describes a second shift in librarians' thinking about library security issues in 1984:

The problem today is not simply preventing the theft of resources ... the whole question of library security is a much larger, more complex matter. The emphasis continues to be on the physical safeguarding of materials; however, the concept must be extended to include the safety of data and files, as well as the 
personal safety of employees and library users. ${ }^{5}$

The increase in the number of articles in Library Literature dealing with library security in the 1960 s as compared with the 1950 s (385\%), and the addition of subject headings in Library Literature for "vandalism" (1964) and "library protection systems" (1970) are indicative of librarians' growing attention to many types of security issues. ${ }^{6}$

Recognition that staff and patrons may themselves perpetrate acts of disruption or violence is increasingly evident in the literature. Writing about "insider" crimes in 1998, Sara Behrman gave examples of "fraud, embezzlement, theft, larceny, mutilation of library materials, falsification of records, misuse of public funds, policy violations and harassment." ${ }^{7}$

Do libraries have particular characteristics that make them vulnerable to crime? On the basis of the data collected from over 1,700 libraries, ${ }^{8}$ Alan Jay Lincoln concluded that major risk factors for libraries are "ease of access" and the library's hours of operation:

The schedules of many libraries may facilitate crime and disruption. Often the library is the only public building that is open after dark and on weekends. The late night hours can be particularly problematic. ${ }^{9}$

Safety and security, already a challenge for libraries during regular hours, are even more challenging during extended hours. In 1990, Mary Ellen Heim stated that the four factors to consider when expanding hours in an academic library setting are "security, staffing, funding, and public relations." ${ }^{10}$ Heim defines security as "the protection of people, collections, and facilities," and adds that "the questions of what safety measures must be addressed and who will be responsible for taking them is a high priority consideration." ${ }^{11}$ In their 1998 discussion of academic library hours, Scott DiMarco and Scott Van Dam concurred: their concerns were staffing, services, and security, the latter including the safety of employees, patrons, and the facility and its contents. ${ }^{12}$

With regard to extended hours and incidents of crime in libraries, Alan Jay Lincoln reported in 1984 that libraries in North
Carolina were more likely to change the schedule than libraries in other states as a response to crime and disruptive behavior:

Thirty states never had to close a library as a result of crime and disruption. Twenty of the states reportedly never changed their hours because of crime. Among the states that did have these problems, California was most likely to have closed a library, and Tennessee was most likely to have closed a branch due to crime.

Changing the schedule occurred most frequently in North Carolina. ${ }^{13}$

Since then, at least one library in North Carolina has closed due to problems with crime. ${ }^{14}$

Why are libraries extending hours despite clear indications that such an action may magnify security and safety challenges? North Carolina libraries, like libraries elsewhere, are experiencing rising expectations and demands for increased hours. Whether rising expectations for increased access are ultimately due to general socio-economic conditions and trends, or to other causes, the result is the same. To meet the needs of library users, libraries are under increasing pressure to extend hours.

People care about when the library is open. Since 1981, Library Literature has published at least 66 citations of articles about library hours, 38 by U. S. authors and 28 by European. Organized protests may occur when hours are reduced. Patrons may petition to restore hours. Voters may approve increased support or oust politicians blamed for reductions in hours. Library staff may organize action to address concerns about library hours. "Enthusiasts" who want the library open twentyfour hours are not limited to North Carolina or the United States. The challenge for librarians is to meet the needs of library patrons while responsibly doing all possible to reduce safety and security risks, a challenge more difficult to overcome when hours are extended.

Librarians are correct to take potential threats seriously. By becoming knowledgeable about preventive steps, they can address perceptions about the safety and security of staff, pa-

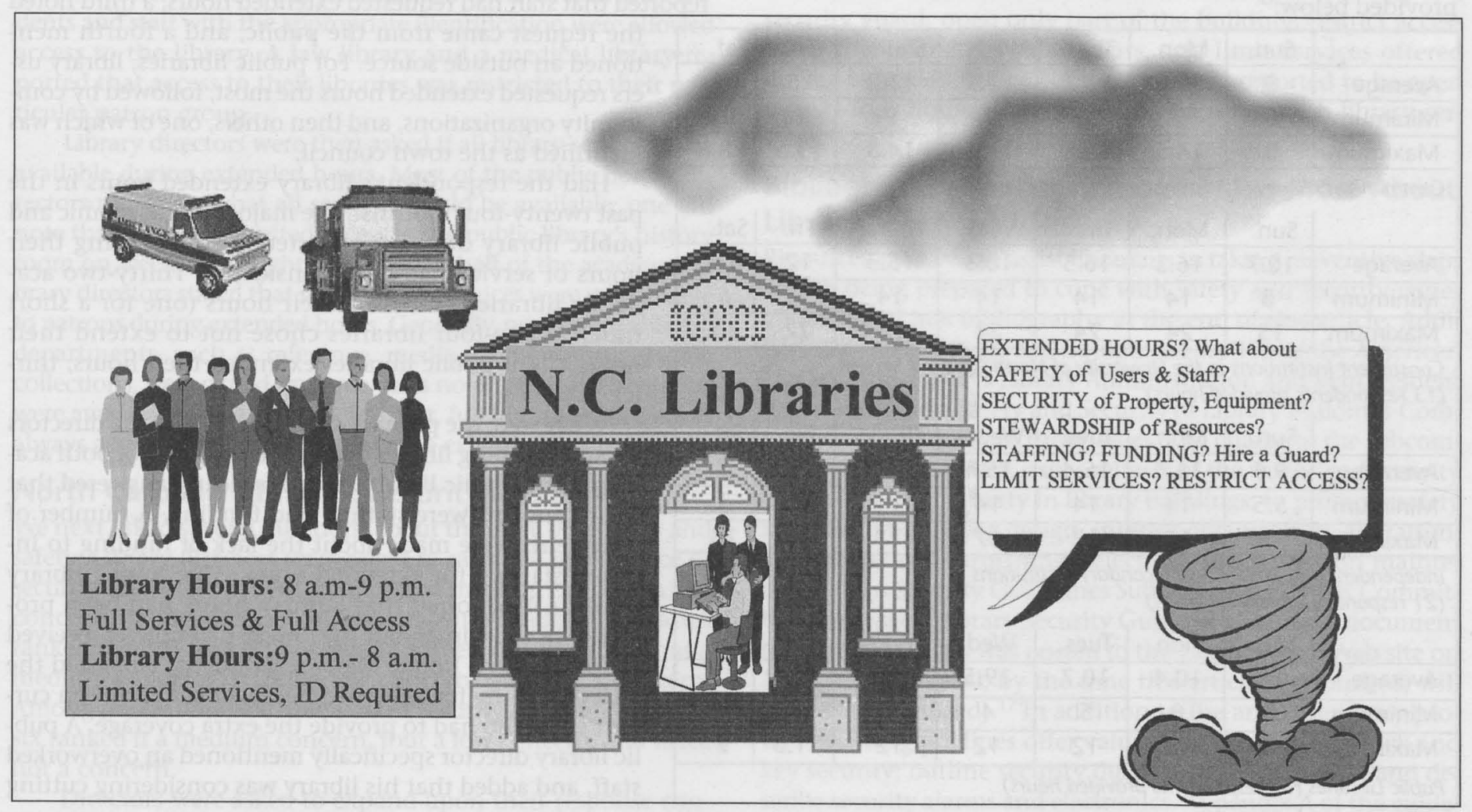


trons, and resources. Perceptions do matter, and perceptions of increased vulnerability in the wake of the Littleton, Colorado, high school shootings have heightened fears of crime in public places. While it is true, as William Moffitt noted in 1994, that 'There is nothing inherently 'libraryish' about violent crime ... it occurs in all sectors of society," 15 librarians' concerns about taking steps and actions to address safety and security concerns are realistic, responsible and necessary.

\section{North Carolina Libraries: Hours of Service}

In March 1999, we mailed out a survey on the security and safety issues accompanying the extension of hours to the directors of 200 North Carolina libraries, 72 public and 128 academic. The latter includes the 16 UNC campuses, the 56 community colleges, 9 AHECs, 3 health sciences libraries, 5 law libraries, and 39 private colleges. The deadline for returning the surveys to the authors was April 19, 1999. Of the 200 surveys mailed out, the authors received 143 , or $71.5 \%$ in return, 100 (50\%) from academic libraries, and 43 (21.5\%) from the public libraries.

The survey began with two questions. First, directors were asked if inquiries about extending hours in the last twenty-four months had been made at the library. Second, they were asked if their libraries had considered extending hours in the last twenty-four months. The answer to each question was either yes or no. If a survey respondent answered "no" to both questions, he or she was asked to stop at that point and return the survey. If either or both questions were answered with a "yes," the respondent was instructed to complete the remaining survey questions. Of the 143 surveys received, forty-seven, or 32.9 percent, answered "no" to the first two questions. A few respondents, however, did answer some of the additional survey questions. In one instance, an academic library extended its service to twenty-four hours, five days a week, more than twenty-four months ago.

To develop a complete picture of library hours in North Carolina, we sought information about a library's current hours of operation. Descriptive summary data on library hours is provided below:

\begin{tabular}{|l|c|c|c|c|c|c|c|}
\hline & Sun. & Mon. & Tues. & Weds. & Thurs. & Fri. & Sat. \\
\hline Average & 0 & 13.2 & 13.2 & 13.2 & 13.2 & 8.5 & 2.1 \\
\hline Minimum & 0 & 9 & 9 & 9 & 9 & 4 & 0 \\
\hline Maximum & 0 & 14.5 & 14.5 & 14.5 & 14.5 & 13.5 & 8 \\
\hline
\end{tabular}

Community Colleges (27 respondents provided hours)

\begin{tabular}{|l|c|c|c|c|c|c|c|} 
& Sun. & Mon. & Tues. & Weds. & Thurs. & Fri. & Sat. \\
\hline Average & 10.7 & 16.3 & 16.3 & 16.3 & 16.3 & 12 & 8.6 \\
\hline Minimum & 8 & 14 & 14 & 14 & 14 & 9 & 6 \\
\hline Maximum & 15 & 24 & 24 & 24 & 24 & 22 & 13 \\
\hline
\end{tabular}

Constituent Institutions in the University of North Carolina System

(13 respondents provided hours)

\begin{tabular}{|l|c|c|c|c|c|c|c|} 
& Sun. & Mon. & Tues. & Weds. & Thurs. & Fri. & Sat. \\
\hline Average & 9.6 & 15.4 & 15.4 & 15.4 & 15.3 & 9.9 & 7 \\
\hline Minimum & 5.5 & 14 & 14 & 14 & 14 & 8.5 & 3 \\
\hline Maximum & 14 & 17 & 17 & 17 & 17 & 13 & 13 \\
\hline
\end{tabular}

Independent and Private PostSecondary Institutions

(21 respondents provided hours)

\begin{tabular}{|l|c|c|c|c|c|c|c|} 
& Sun. & Mon. & Tues. & Wed. & Thurs. & Fri. & Sat. \\
\hline Average & 1.3 & 10.4 & 10.7 & 19.5 & 10.6 & 8.7 & 7.2 \\
\hline Minimum & 0 & 0 & 5 & 4 & 5 & 5 & 4 \\
\hline Maximum & 4 & 12 & 12 & 12 & 12 & 11.5 & 9 \\
\hline
\end{tabular}

No libraries reported being open twenty-four hours, seven days a week, with services. North Carolina State University, rumored to have twenty-four hour, seven-day-a-week service during academic semesters, actually closed from 10:00 p.m. until 9:00 a.m. the following morning on both Friday and Saturday nights during fall 1998 and spring 1999 semesters. NCSU reports that "between midnight and 7:00 a.m., building access is limited to individuals with a current university picture ID." Some libraries are experimenting with twenty-four hour service during exam times, as did Greensboro College. Duke University's Perkins Library reports its old building is available by key-card access to students twenty-four hours, seven days a week; however, there are no library services connected with the privilege.

As expected, academic libraries are more likely than public libraries to report pressures to experiment with extending hours to the twenty-four hour model. Library administrators' comments show concern that, while demands and pressures for extending hours exist, actual use is too low to warrant opening extended hours. Additional concerns are that the library is being used as a study hall or a computer lab, with limited services and restricted access during extended hours.

\section{North Carolina Libraries: Extending Hours}

In seeking information about the extension of library hours, we began by asking who had expressed interest in increased hours of operation. For academic libraries, the survey respondent was given three choices: students, faculty, or administration. For public libraries, the choices were community users, library users, and others. The respondent could circle one or more of these sources. Who, then, was most interested in extended library hours? For academic libraries this demand was made by students, followed by administrators, and then faculty. In some surveys the request came from students and administration, students and faculty, and, in eight cases, students, faculty, and administration. One respondent noted that extended library hours had been a recommendation of a SACS (Southern Association of Colleges and Schools) study. Another reported that staff had requested extended hours; a third noted the request came from the public; and a fourth mentioned an outside source. For public libraries, library users requested extended hours the most, followed by community organizations, and then others, one of which was identified as the town council.

Had the respondent's library extended hours in the past twenty-four months? The majority of academic and public library directors reported that extending their hours of service had been considered. Thirty-two academic libraries extended their hours (one for a short time); thirty-four libraries chose not to extend their hours. Eight public libraries extended their hours; thirteen did not.

What were the primary concerns held by the directors about extending library hours? The majority of both academic and public library directors clearly answered that their concerns were staffing and funding. A number of comments were made about the lack of funding to increase staffing for extended hours. One public library director mentioned that Sunday hours had been proposed for the winter, but the library had not yet received funds for those hours. Many respondents lamented the lack of staffing for extended hours, or the strain on current staff who had to provide the extra coverage. A public library director specifically mentioned an overworked staff, and added that his library was considering cutting 
hours at certain locations. An academic library director wrote that, even though they wanted to serve their customers, there was not enough staff to cover extra hours. Several wondered if low usage would justify the costs of keeping the library open, and one respondent reported that, having tried extended hours, usage was so low the extended hours were canceled.

Although much emphasis was placed upon staffing and funding, safety and security were critical concerns as well, especially for the directors of academic libraries. The security of patrons and the library building was mentioned by one director; another was concerned about the security of student workers at the circulation desk until 2:00 a.m. Once again, funding came into play. Wrote one respondent, "Staffing, funding!" Another respondent noted the costs of keeping the facility open, including heating, cooling, and security. Another wondered "whether enough students would use the library to justify extra expense in salaries, heat/air, and security." Still another commented, "Staffing, costs, security." That simple statement expresses the chief concerns of library directors when considering extending library hours.

Library directors were asked to describe any extended hours and any restrictions on access or limitations on services that would apply to the extended hours. In general, public libraries offered full services in their extended hours. For academic libraries, extended hours fell into two large categories. First, a number of libraries offered extended hours only at exam time. One library, for instance, provides twenty-four hour access during final exams; between 11:00 p.m. and 7:00 a.m. a security guard staffs the building with some student workers. A few libraries are open longer hours throughout the semester, but are used as study halls or computer labs. Staffing is minimal, and there is no library service, such as reference, open to patrons.

Directors also were asked if library access during extended hours was restricted to a particular clientele. The large majority of respondents from both academic and public libraries stated there were no restrictions for clientele. One academic respondent noted that after midnight the library was available only to those who had a key-card. Another stated that only students and staff with the appropriate identification were allowed access to the library. A law library and a medical library reported that access to their libraries was restricted to their particular patron group.

Library directors were then asked if all library services were available during extended hours. Most of the public library directors responded that all services would be available; one did note that there was limited access to the public library's history room on weekends. Slightly more than half of the academic library directors stated that some library services were unavailable to patrons during extended hours. Generally, one or more library departments, such as reference, media, circulation or special collections, were closed. In some cases no professional librarians were available to offer service. In short, full library service is not always available to patrons during the extended hours.

\section{North Carolina Libraries: Security and Safety}

We next asked several questions about the issue of security and safety. Library directors were asked to rank the importance of security and safety as a high concern, a medium concern, a low concern, or not a concern. Twenty-nine academic libraries ranked security as a high concern; fifteen ranked security as a medium concern; sixteen a low concern; four, not a concern. Among public libraries, nine ranked security as a high concern, six ranked it a medium concern, four a low concern, and three not a concern.

Directors were asked to expand upon their response con- cerning security, and twenty-two academic library directors and six public library directors did so. Security for staff was mentioned; in at least two academic libraries security guards are used during hours of operation. One respondent reported that campus police had been responsive to library needs; another noted that a campus security guard is available on campus twenty-four hours a day, and hand radios were available in the library for getting in touch with the guard. Those in rural settings expressed fewer fears about safety. Again, staffing was mentioned as a concern. Security becomes a major challenge for one academic library if staffing is down due to illness. A public library director stated that "when the staffing level is too low, abusers of library services have ample opportunities to strike."

Library directors were then asked to describe any steps or actions taken to address security and safety concerns during extended hours. One public library director responded that security was not a concern because the library branch with extended hours is located across the street from the local police station. Not all academic or public libraries have such an ideal location. One solution has been to install security cameras at all egress doors (although the librarian who reported this mentioned that this was done out of general concern, and not just because of extended hours). Academic libraries rely more on campus police. In some cases campus police visit the library; in others, library staff stay in touch with campus security by phone or walkie-talkie. Others have hired security guards, although one library's request for a security guard was not granted by campus administration. Escort service for students leaving the library is offered on some campuses.

\section{Survey Conclusions}

The majority of respondents reported pressures to extend hours, and more than two thirds of respondents reported considering safety and security concerns as factors of high to medium importance in making decisions about extending hours. Common patterns for libraries that have extended hours to the twenty-four hour model are to limit staffing to students or a security guard, open only part of the building, restrict access more than during regular hours, and limit services offered during extended hours. No libraries were reported to be open twenty-four hours a day, seven days a week, with library services.

\section{Bibliographic Resources for Learning More About Library Safety and Security}

Resources available to assist librarians in taking preventive steps and in being prepared to cope with safety and security issues are included in a bibliography at the end of this article. Additionally, the Buildings and Equipment Section of the American Library Association's Library Administration and Management Association has a Safety and Security of Library Buildings Committee which addresses these issues. The charge to the subcommittee is "to deal with issues related to the safety and security of persons and property in library buildings; to promote safety measures in building design, interior organization, alteration, equipment and furnishing, selection, and collection maintenance." ${ }^{16}$ A Security Guidelines Subcommittee of this Committee developed "Library Security Guidelines;" a draft document of these guidelines was posted to the Committee's Web site on April 12, 1999 (and, by the time this article is published, will have been finalized). ${ }^{17}$ In addition to fire and emergency protection, the guidelines offer valuable suggestions on lock and key security; outline security duties and security staff; and describe security alarms and electronics. Appendix A of the guide- 
lines presents security staff qualifications and Appendix B provides library directors with staff pre-employment screening guidelines. The final version of these guidelines should be very useful to any library director addressing the issue of security.

The Buildings and Equipment Section also has a Library Safety/Security Discussion Group that is "a forum for librarians interested in safety and security issues as they relate to the design, construction, renovation, and equipment of library facilities." 18 The group also serves "to identify and discuss common concerns and to examine alternative solutions to problems."19 The Group has set up Safety-L, an electronic list on the safety and security of libraries.

Susan Hildreth, a survivor of the 1993 Sacramento Public Library violence in which two reference librarians were murdered, stated "you can never be prepared for something like that." ${ }^{20}$ Perhaps not; however, it is important to provide plans and training for handling emergency situations. As Dennis Day, director of Salt Lake City Public Library said in 1994 when an armed man entered and began taking hostages, "Dealing with emergency situations and disruptive patrons, personal safety and a thorough understanding of evacuation procedures are critical concerns for all libraries ... Our experience strongly indicates that a trained, committed staff and effective planning can and does make a difference." 21

\section{References}

1 "News Fronts USA," American Libraries 30 (June/July 1999): 26-28.

2 Ralph Munn, "The Problems of Theft and Mutilation," Library Journal 60 (1935): 589-592.

3 Arthur E.Bostwick, "A New Kind of Inventory," Library Journal 42 (1917): 369-371.

4 Arthur E.Bostwick, "Frequency of Inventory," Library Journal 52 (1927): 827-828.

5 Thomas W. Shaughnessy, "Security: Past, Present and Future," in Security for Libraries: People, Buildings, Collections. ed. Marvine Brand (Chicago: ALA, 1984): 2.

6 Ibid, 1.

7 Sara Behrman, "When Trust Isn't Enough," American Libraries 29 (May, 1998): 72.

8 Alan Jay Lincoln, Crime in the Library: A Study of Patterns, Impact and Security. (New York: Bowker, 1984).

9 Alan Jay Lincoln, "Introduction," Library Trends 33 (Summer 1984): 8.

10 Mary Ellen Heim, "Open Twenty-Four Hours: A Case Study," Occasional Papers, no. 187 (Champaign-Urbana, IL: University of Illinois Graduate School of Library and Information Sciences, 1990), 4.

11 Ibid, 4.

12 Scott DiMarco and Scott van Dam, "Late Night in an Academic Library: Issues, Concerns, Planning," Library \& Archival Security 14 (1998): 10.

13 Lincoln, 112.

14 Leonard Kniffel, "Crime Forces Branch Library Out of Charlotte, N.C., Mall," American Libraries 22 (Feb. 1991): 122.

15 Evan St. Lifer, Colleen McLaughlin, and Wilda W. Williams, "How Safe Are Our Libraries," Library Journal 119 (Aug., 1994): 35.

16 "LAMA BES Library Safety and Security of Library Buildings," (June 14, 1999). <http://www.ala.org/lama/committees/ bes/sslb.html>

17 "Library Security Guidelines DRAFT DOCUMENT APRIL 12, 1999." (June 14, 1999). <http://www.ala.org/lama/committees/ bes/sslbguidelines.html>

18 "LAMA BES Library Safety/Security Discussion Group." June 14, 1999). <http://www.ala.org/lama/committees/bes/lss.html>
19 Ibid.

20 St. Lifer, 39.

21 Ibid, 37.

22 "Library Security Guidelines DRAFT DOCUMENT APRIL 12, 1999." (June 14, 1999). <http://www.ala.org/lama/committees/ bes/sslbguidelines.html>

\section{Library Safety and Security Bibliography}

A. J. Anderson, "How Do You Manage?," Library Journal 121 (Mar. 1, 1996): 59-60.

Jennifer W. Arns, "Health and Safety Issues in the Library Workplace," Library Personnel News 3 (Fall 1989): 49.

Tom R. Arterburn, "Librarians: Caretakers or Crimefighters," American Libraries 27 (Aug. 1996): 32-4.

Randall L. Atlas, "Designing Crime-Free Environments: Making Our Buildings Safer," Library Administration and Management 11 (Spring 1997): 88-93.

Colin Baddock, "Countering Crime: A Model Training Program for Managers," in Security and Crime Prevention in Libraries (Aldershot, UK: Ashgate, 1992), 248-266.

Philip Bean, "An Overview of Crime in Libraries and Information Services," in Security and Crime Prevention in Libraries (Aldershot, UK: Ashgate, 1992), 13-31.

Carol D. Billings, "Rights and Obligations of a Librarian," LLA Bulletin 59 (Winter 1996): 128-34.

Richard W. Boss, "Collection Security," Library Trends 33 (Summer 1984): 39-48.

Betty Braaksma, "Zero Tolerance at the Library: the Work of the Thunder Bay Public Library's Security Task Force," Library \& Archival Security 14 (1998):43-9.

Robert Chadbourne, "Disorderly Conduct: Crime and Disruptive Behavior in the Library," Wilson Library Bulletin 68 (March 1994):23-5.

Otis A. Chadley, "Campus Crime and Personal Safety in Libraries," College \& Research Libraries 57 (July 1996): 385-390.

Michael Chaney and Alan F. MacDougall, eds. Security and Crime Prevention in Libraries. (Aldershot, UK: Ashgate, 1992).

Jennifer E. Chilcoat, "Creating a Safer Workplace-Personal Safety Considerations for Libraries," Arkansas Libraries 50 (Oct. 1993): 18-20.

James H. Clark, "Making Our Buildings Safer: Security Management and Equipment Issues," Library Administration and Management 11 (Summer 1997): 157-161.

Wilbur B. Crimmin, "Institutional, Personal, Collection, and Building Security Concerns," in Security for Libraries: People, Buildings, Collection, ed. Maurine Brand (Chicago: ALA, 1982).

Patricia J. Davis, "Libraries in Crisis: Safety and Security in Today's Library; or, I've Seen Fire and I've Seen Rain," Texas Library Journal 71 (Summer 1995): 90-3.

Patty Duitman, "Perils, Pits and Pitfalls in the Library," PNLA Quarterly 60 (Winter 1996): 11-12.

George M. Eberhart, "Guidelines Regarding Thefts in Libraries," in The Whole Library Handbook 2. (Chicago:ALA, 1995) 436-439.

Paulette D. Entrekin, "Crime and Violence in Mississippi Libraries: A Preventive Approach," Mississippi Libraries 59 (Summer 1995): 36-7.

"Experts Advise How to Minimize Library Crime," (LAMA program at the 1992 ALA Conference; reprinted from Nicolet Compass 4/93), The Unabashed Librarian 88 (1993): 31.

Lillian N. Gerhardt, "Safe at Work?," School Library Journal 39 (Feb. 1993): 4.

Mary M. Harrison, Alison H. Armstrong and David Hollenbeck, 
"Crime in Academic Libraries," in Patron Behavior in Libraries: A Handbook of Positive Approaches to Negative Situations, by Beth McNeil and Denise J. Johnson (Chicago: ALA, 1996), 87-94.

Gregory G. Heid, "Health and Safety Issues," in The Personnel Manual: An Outline for Libraries, 2nd ed. Charles E. Krantz and Valerie A. Platz (Chicago: ALA,1993), 44-46.

John Houlgate and Michael Chaney, "Planning and Management of a Crime Prevention Strategy," in Security and Crime Prevention in Libraries. (Aldershot, UK: Ashgate, 1992), 46-49.

David H. Johansson, "Library Material Theft, Mutilation, and Preventive Security Measures," Public Library Quarterly 15 (1996): 51-66.

Daniel P. Keller, "Special Problems in the Library Setting," Library Administration and Management 11, (Summer 1997): 161-65.

Alan Jay Lincoln, "Community Crime Prevention," Library \& Archival Security 9 (1989): 49-57.

Alan Jay Lincoln and Carol Zall Lincoln, "Controlling Crime: a Security Checklist," Library \& Archival Security 8 (Spring/ Summer 1986): 145-154.

Barry V. Lipinski, "A Practical Approach to Library Security," New Jersey Libraries 27 (Fall 1994): 19-20.

Beth McNeil and Denise J. Johnson, eds., Patron Behavior in Libraries: A Handbook of Positive Approaches to Negative Situations (Chicago:ALA, 1996).

John Morris, "Planning and Design for Safety and Security," PNLA Quarterly 52 (Summer 1988): 22-4.

John Morris, "Protecting the Library From Fire," Library Trends 33 (Summer 1984): 49-56.

Shelley Mosley, Anna Caggiano, and John A. Charles, "The 'Self-Weeding' Collection," Library Journal 121 (Oct. 15,
1996): 38-40.

James B. Nelson, "Safety in the Public Library," The Unabashed Librarian 88 (1993): 9-13.

Roland C. Person and Nelson A. Ferry, "Cutting Down on Crime in the Library," College \& Research Libraries News 55 (July/ Aug. 1994):428-9.

Kate W. Ragsdale and Janice Simpson, "Being on the Safe Side," College \& Research Libraries News 57 (June 1996): 351-4.

John Ramsay, "Safety in Small Libraries, Revisited," The Unabashed Librarian 94 (1995): 5-6.

F. W. Ratcliffe, "Changing Times? Crime and Security as a Major Issue in Libraries," in Security and Crime Prevention in Libraries, (Aldershot, UK: Ashgate, 1992), 1-12.

Ilene F. Rockman, "Coping with Library Incidents," College \& Research Libraries News 56 (July/Aug. 1995): 456-7.

Thomas W. Shaughnessy, "Security: Past, Present and Future: Checklist for a Security Survey," in Security for Libraries: People, Buildings, Collections, ed. Marvine Brand (Chicago: ALA, 1982).

Bruce A. Shuman, "The Devious, the Distraught and the Deranged: Designing and Applying Personal Safety into Library Protection," Library \& Archival Security 14 (1997): 53-73.

Bruce A. Shuman, "Designing Personal Safety into Library Buildings," American Libraries 27 (Aug. 1996): 37-9.

Herbert Snyder, "Protecting Our Assets: Internal Control Principles in Libraries," Library Administration and Management 11 (Winter 1997): 42-46.

Thomas M. Steele, "Managing Legal Liability," Library Administration and Management 11 (Spring 1997): 94-102.

Robert L. Willits, "When Violence Threatens the Workplace: Personnel Issues," Library Administration and Management 11 (Summer 1997): 166-171.

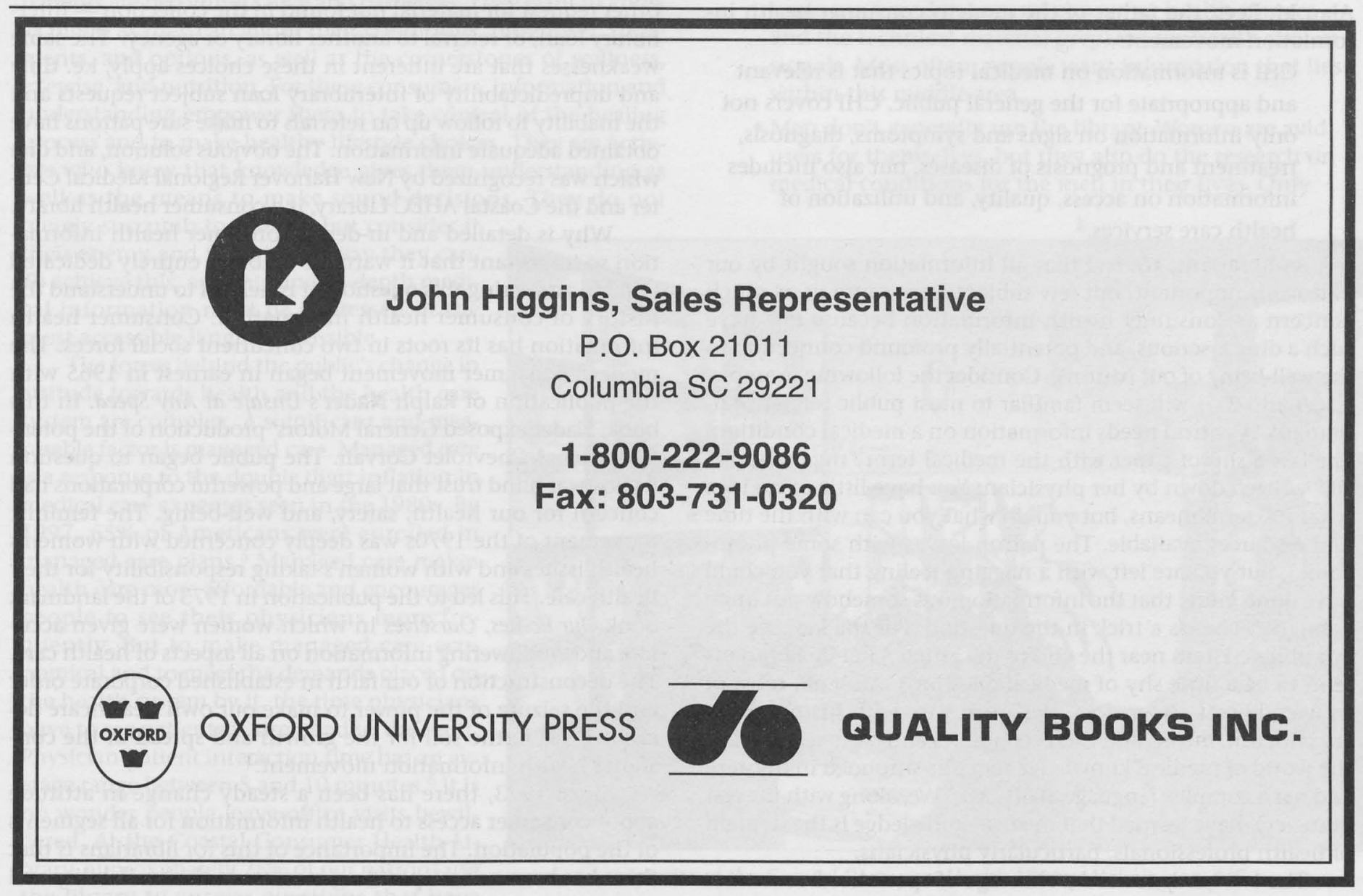

